\title{
QUALIDADE FÍSICA, VIABILIDADE E DORMÊNCIA DE SEMENTES RECÉM- COLHIDAS DE CAPIM-GORDURA (Melinis minutiflora P. Beauv.) ${ }^{1}$
}

\author{
RICARDO CARMONA²; CARLOS ROMERO MARTINS ${ }^{3}$
}

\begin{abstract}
RESUMO - O capim-gordura tem sido uma importante invasora em áreas de proteção ambiental na região Central do Brasil, devido, entre outros aspectos, à sua elevada capacidade de reprodução e dispersão. No presente trabalho teve-se como objetivo avaliar a percentagem de espiguetas cheias, a viabilidade e a dormência de sementes recém-colhidas de capim-gordura, provenientes de diferentes locais de coleta. Foram utilizadas sementes das cultivares Roxo e Cabelo-de-Negro, importantes gramíneas invasoras de áreas de proteção ambiental nos cerrados brasileiros, coletadas em três unidades de conservação do Distrito Federal, Brasil: Parque Nacional de Brasília, Reserva Ecológica do IBGE e Estação Ecológica de Águas Emendadas. Avaliou-se a percentagem de sementes cheias (contendo cariopse) mediante separação, contagem e pesagem das frações espiguetas cheias e vazias e; a viabilidade e a dormência dessas sementes, pelo teste de germinação utilizando-se apenas sementes cheias. Foi observada grande variação na ocorrência de sementes cheias em função do local de coleta, especialmente na cultivar Roxo (17,5\% a 36,1\%). O local de coleta também afetou a dormência das sementes de ambas as cultivares $(20 \%$ a $80 \%)$ e a viabilidade das sementes apenas da cultivar Roxo ( $80 \%$ a $96 \%$ ). O teste de germinação em temperaturas alternadas de $20-30{ }^{\circ} \mathrm{C}$, em solução de nitrato de potássio a $0,5 \%$ com luz foi eficiente para avaliar a viabilidade das sementes enquanto o teste a $25^{\circ} \mathrm{C}$, em água e no escuro foi eficiente para estimar a dormência das sementes. Esses resultados sugerem que certas características das sementes dessa espécie, como elevada viabilidade e dormência, podem contribuir para sua grande dispersão.
\end{abstract}

Termos para indexação: germinação, esterilidade de espiguetas, invasoras, áreas de proteção ambiental.

\section{PHYSICAL QUALITY, VIABILITY AND DORMANCY OF RECENTLYHARVESTED Melinis minutiflora P. Beauv. SEEDS}

\begin{abstract}
In protected areas of the Central Region of Brazil Melinis minutiflora (molasses grass, stinkgrass) is an important weed due to, among other reasons, its reproductively and dispersion. We evaluated spikelet sterility and seed viability and dormancy for two M. minutiflora cultivars (Roxo and Cabelo-de-Negro) collected in three conservation units in the Brazilian cerrado (hot, semihumid savanna): Parque Nacional de Brasília, Distrito Federal; Reserva Ecológica do IBGE; Estação Ecológica de Águas Emendadas. The percentage of full seeds (i.e. those containing caryopsis) was evaluated by separating, counting and weighing full and empty spikelets, while seed viability and dormancy were evaluated using germination tests on full seeds. The collection site affected not only the percentage of full seeds, especially for cv. Roxo (17.5\% to 36.1\%), but also seed dormancy in both cultivars $(20 \%$ to $80 \%)$ and seed viability in cv. Roxo $(80 \%$ to $96 \%)$. Seed viability was adequately
\end{abstract}

${ }^{1}$ Submetido em 08/05/2009. Aceito para publicação em 19/11/2009.

${ }^{2}$ Agr. Ph.D. Professor Associado, Faculdade de Agronomia e Medicina Veterinária, Universidade de Brasília. 70.910-970 Brasília-DF. e-mail: rcarmona@unb.br.

${ }^{3}$ Eng. Florestal Dr. em Ecologia, Ibama/Sede/Diretoria de Licenciamento, 70.8118-900 Brasília-DF. carlos.martins@ibama.gov.br. 
evaluated using germination tests in $0.5 \%(\mathrm{w} / \mathrm{v})$ potassium nitrate at alternating temperatures $\left(20{ }^{\circ} \mathrm{C}\right.$ and $30^{\circ} \mathrm{C}$ ) in the light, while seed dormancy was adequately estimated in water at $25^{\circ} \mathrm{C}$ in darkness. These results suggest that characteristics such as seed dormancy and high seed viability can contribute to the dispersion of M. minutiflora seeds in wildlife protection areas.

Index terms: germination, spikelet sterility, weeds, wildlife protection areas.

\section{INTRODUÇÃO}

O capim-gordura provavelmente foi introduzido no território brasileiro no século XIX, de forma acidental, por ocasião do tráfico intenso de escravos (Parsons, 1972; Filgueiras, 1990). O centro de origem dessa espécie é o continente africano e o território brasileiro é caracterizado como centro de desenvolvimento ou dispersão (Vello, 1975). Segundo Bogdan (1977), o gênero Melinis contém de 20 a 25 espécies. No Brasil, ocorrem apenas as espécies Melinis minutiflora e Melinis repens e, entre as cultivares de Melinis minutiflora, as mais conhecidas são Roxo, Cabelo-de-Negro, Branco e Francano (Brasil, 1953), sendo encontradas no Distrito Federal apenas as duas primeiras.

Durante aproximadamente 120 anos, o capim-gordura e o capim jaraguá (Hyparrhenia rufa) foram as principais forrageiras utilizadas para a formação de pastagens no Brasil Central. Na década de sessenta do século XX, dos 123 milhões de hectares de pastagens existentes no Brasil, cerca de 30 milhões eram cultivados com capimgordura. Nos anos setenta, os pecuaristas iniciaram um processo de substituição do capim-gordura por espécies mais produtivas do gênero Urochloa (=Brachiaria), tais como $U$. decumbens, $U$. brizantha, $U$. ruzizienses e $U$. humidicola (Curado e Costa, 1980; Aronovich e Rocha, 1985).

Entretanto, o capim-gordura persistiu nessa região, mudando seu status de espécie cultivada para indesejada, devido à sua forte capacidade de interferência com espécies nativas, principalmente com outras gramíneas (Filgueiras, 1990). Atualmente, a presença dessa espécie é bastante comum no Cerrado, especialmente nas áreas de unidades de conservação (Pivello, 1992). No Distrito Federal, ocorre no Parque Nacional de Brasília, na Reserva Biológica da Contagem, na Estação Ecológica de Águas Emendadas, no Jardim Botânico, na Reserva Ecológica do IBGE e na Floresta Nacional de Brasília, entre outras localidades. A extensão das áreas colonizadas por essa gramínea nas regiões protegidas do Distrito Federal, à exceção do Parque Nacional de Brasília, não foi ainda devidamente avaliada (Martins, 2006).

Uma das principais características do capim-gordura que condicionam seu rápido desenvolvimento e expansão refere-se à sua capacidade reprodutiva. Suas sementes são produzidas em grandes quantidades e são facilmente disseminadas pelo vento (Filgueiras, 1990; Freitas \& Pivello, 2005). O conhecimento das características reprodutivas dessa espécie pode constituir importante ferramenta para a proposição de métodos racionais de manejo (Allred, 1982), reduzindo assim os problemas por ela causados em unidades de conservação.

Objetivou-se com esta pesquisa avaliar o efeito do local de produção na viabilidade, dormência e ocorrência de espiguetas cheias em sementes recém-colhidas de capim-gordura.

\section{MATERIAL E MÉTODOS}

\section{Coletas de sementes}

Unidades de dispersão de capim-gordura (espiguetas cheias e vazias) das cultivares Roxo e Cabelo-de-Negro foram coletadas nas seguintes localidades do Distrito Federal, Brasil: Parque Nacional de Brasília (PARNA Brasília coordenadas $15^{\circ} 44^{\prime} \mathrm{S}$ e $47^{\circ} 57^{\prime} \mathrm{W}$ ), Reserva Ecológica do IBGE (RECOR IBGE - coordenadas $15^{\circ} 56^{\prime}$ 'S e $47^{\circ} 53^{\prime}$ W) e Estação Ecológica de Águas Emendadas (ESEC AE coordenadas $15^{\circ} 32^{\prime}$ S e $47^{\circ} 33^{\prime} \mathrm{W}$ ).

Para fins de coleta, foram cortadas manualmente e aleatoriamente 10 inflorescências de cada cultivar, no mês de junho de 2004, mediante o método de caminhamento através de transectos imaginários. O material cortado foi secado à sombra, pelo período de dois meses, no Laboratório de Sementes da Faculdade de Agronomia e Medicina Veterinária da Universidade de Brasília. O material foi trilhado e limpo manualmente e as sementes acondicionadas em sacos de papel permeável. 


\section{Parâmetros estudados}

Percentagem e massa das sementes cheias (contendo cariópse) - foram determinadas mediante separação, contagem e pesagem das frações espiguetas cheias e vazias. As espiguetas cheias foram separadas das vazias mediante uso de assoprador (marca General Seed Blower) por três minutos, previamente regulado na abertura 4 . Devido à ocorrência de aristas nas sementes da cultivar Roxo, em cada operação no assoprador, o peso máximo de cada porção de sementes não excedeu a $0,10 \mathrm{~g}$ para evitar o entrelaçamento entre as sementes.

Testes de germinação - conduzidos apenas com sementes cheias. Foram realizados em câmaras de germinação tanto nas temperaturas alternadas de 20$30{ }^{\circ} \mathrm{C}$ (16/8 horas) com luz florescente branca durante a temperatura mais elevada em nitrato de potássio a $0,5 \%$, como na temperatura de $25{ }^{\circ} \mathrm{C}$ no escuro em água. As condições descritas para o teste em temperaturas alternadas, por serem altamente estimulantes de germinação para espécies gramíneas (Carmona et al., 1999), foram testadas para estimar a viabilidade das sementes. Já as condições de temperatura constante foram usadas para estimar a dormência das sementes dessa espécie (Carmona et al., 1999). Os testes de germinação foram realizados sobre papel, em placas de petri de poliestireno transparente forradas com duas folhas de papel filtro umedecidas com nitrato de potássio ou água destilada, na proporção de 2,5 vezes o peso do papel seco, de acordo com o respectivo teste.

As contagens das sementes germinadas (emissão de, pelo menos, $2 \mathrm{~mm}$ de radícula e/ou coleóptilo) foram realizadas diariamente nos testes em presença de luz, afim de monitorar-se a evolução do processo germinativo, reumedecendo o substrato com água destilada sempre que necessário. Para avaliar a germinação na ausência de luz, as placas de petri foram envoltas por duas folhas de papel alumínio. Nesse caso, as placas foram seladas com fita adesiva para evitar o ressecamento do substrato. Os testes no escuro foram avaliados uma única vez, ao final das avaliações em presença de luz, aos trinta dias após montagem dos mesmos.

Todos os tratamentos constaram de quatro repetições de 100 sementes cheias (Brasil, 1992) analisados em delineamento inteiramente casualizado. Para fins de análise estatística, os dados obtidos nos testes de germinação, em percentagem, foram previamente transformados em arco seno $\sqrt{ } \% / 100$, para a normalização da sua distribuição. Quando houve significância de acordo com o teste de F, as médias foram comparadas pelo teste de Tukey, ao nível de 5\% de probabilidade (Mead et al., 2003).

\section{RESULTADOS E DISCUSSÃO}

Observou-se variação de $17,5 \%$ a $36,1 \%$ na percentagem de sementes cheias na cultivar Roxo de capim-gordura (Tabela 1) entre os diferentes locais estudados. Na cultivar Cabelo-de-Negro, não houve diferença na quantidade de sementes cheias entre os locais estudados, ficando ao redor de $27 \%$. Os valores observados estão de acordo com os relatados em outros trabalhos com capim-gordura, em que esse percentual variou de $25 \%$ a $40 \%$ (Brasil, 1953; Rocha et al. 1966; Freitas e Pivello, 2005). Esses resultados evidenciam que o capim-gordura tem alta taxa de esterilidade natural de sementes. No Brasil, os padrões mínimos aceitáveis de pureza física para a produção de sementes de Melinis minutiflora variam em torno de 30\% (Brasil, 1998).

\section{TABELA 1. Incidência de sementes cheias (\%) em Melinis minutiflora (capim-gordura), cultivares Roxo e Cabelo-de-Negro, coletadas no ano de 2004, em diferentes áreas do Distrito Federal, Brasil.}

\begin{tabular}{ccc}
\hline \multirow{2}{*}{ Local de coleta } & \multicolumn{2}{c}{ Sementes cheias $(\%)$} \\
\cline { 2 - 3 } & Roxo & Cabelo-de-Negro \\
\hline IBGE & $36,1 \mathrm{a}$ & $28,1 \mathrm{a}$ \\
PARNA & $24,8 \mathrm{~b}$ & $27,7 \mathrm{a}$ \\
ÁGUAS & $17,5 \mathrm{c}$ & $24,6 \mathrm{a}$ \\
\hline
\end{tabular}

Médias seguidas da mesma letra nas colunas não diferem entre si pelo teste de Tukey a 5\% de probabilidade. IBGE: Reserva Ecológica do IBGE; PARNA: Parque Nacional de Brasília; ÁGUAS: Estação Ecológica de Águas Emendadas.

As maiores ocorrências de sementes cheias na cultivar Roxo foram observadas nas sementes provenientes da Reserva Ecológica do IBGE, seguida das do Parque Nacional de Brasília e, por último, nas da Estação Ecológica das Águas Emendadas. O efeito de local de coleta na ocorrência de sementes cheias provavelmente indica uma influência genética ou edafo-climática nesse parâmetro, entretanto são necessários mais estudos para elucidar esse fenômeno.

Estudos concernentes à taxa de esterilidade de 
espiguetas em gramíneas nativas ainda são raros no Brasil, contudo Carmona et al. (1999), avaliando as características de sementes de 22 espécies de gramíneas nativas colonizadoras de áreas degradadas no cerrado, observaram que esse parâmetro é bastante variável entre gêneros. Esses autores propuseram uma classificação de acordo com o índice de espiguetas cheias, categorizando como de elevado índice de espiguetas cheias (superior a 50\%) espécies dos gêneros Aristida, Ctenium, Diectomis e Schizachyrium; como intermediário (25\% a 49\%) espécies dos gêneros Andropogon e Hypogynium; como baixo (5\% a 24\%) espécies de Paspalum, Setaria e Thrazia e muito baixo (inferior a 5\%) no gênero Axonopus. De acordo com essa classificação, o capim-gordura pode ser categorizado como espécie com baixo a intermediário índice de espiguetas cheias.

Os testes de germinação de sementes iniciaram no mês de outubro, época do ano coincidente com o início do período chuvoso na região dos Cerrados. As sementes cheias, especialmente da cultivar Roxo, armazenadas durante quatro meses após colheita, tiveram baixa germinação em temperatura constante $\left(25^{\circ} \mathrm{C}\right)$, em água e no escuro (Tabela 2). A exposição das sementes a temperaturas alternadas (20$30{ }^{\circ} \mathrm{C}$ ), nitrato de potássio e luz resultou em germinação superior a $80 \%$ para a cultivar Roxo e superior a $90 \%$ para Cabelo-de-Negro (Tabela 2). Esses resultados confirmam que as temperaturas alternadas usadas juntamente com luz e nitrato de potássio constituem condições estimulantes para a germinação dessa espécie, podendo, dessa forma, serem usadas em testes de viabilidade de sementes de capimgordura. Testes de germinação conduzidos nessas mesmas condições foram estimulantes para sementes de espécies de gramíneas nativas do cerrado, coletadas no Distrito Federal (Carmona et al., 1998).

Apesar da elevada viabilidade das sementes provenientes de todos os locais, observou-se efeito do local de coleta na viabilidade de sementes da cultivar Roxo. Na cultivar Cabelo-de-Negro, o efeito do local de coleta não foi aparente na germinação de sementes sob condições favoráveis, entretanto em temperatura constante e no escuro, esse efeito foi bastante evidente na germinação das sementes, variando de $12 \%$ no Parque Nacional de Brasília a 77\% na Reserva Ecológica de Águas Emendadas (Tabelas 2 e 3). Na cultivar Roxo, o local de coleta afetou a germinação de sementes nas duas condições testadas. A germinação das sementes da cultivar Cabelo-de-Negro foi, de forma geral, superior à das sementes da cultivar Roxo nas duas condições usadas para os testes de germinação (Tabelas 2 e 3).
TABELA 2.Germinação(\%)desementes cheias de Melinis minutiflora, cultivares Roxo e Cabelo-deNegro, em temperaturas alternadas $\left(20^{\circ}-30\right.$ $\left.{ }^{\circ} \mathrm{C}\right)$ com luz e nitrato de potássio e constante $\left(25^{\circ} \mathrm{C}\right)$ no escuro e em água, coletadas em diferentes áreas do Distrito Federal, Brasil, 2004.

\begin{tabular}{lcccc}
\hline \multirow{2}{*}{$\begin{array}{c}\text { Local de } \\
\text { coleta }\end{array}$} & \multicolumn{2}{c}{$\begin{array}{c}\text { Temperatura } \\
\text { alternada }\end{array}$} & \multicolumn{2}{c}{$\begin{array}{c}\text { Temperatura } \\
\text { constante }\end{array}$} \\
\cline { 2 - 5 } & Roxo & $\begin{array}{c}\text { Cabelo- } \\
\text { de-Negro }\end{array}$ & Roxo & $\begin{array}{c}\text { Cabelo- } \\
\text { de-Negro }\end{array}$ \\
\hline IBGE & $93 \mathrm{a}$ & $93 \mathrm{a}$ & $13 \mathrm{a}$ & $28 \mathrm{~b}$ \\
PARNA & $86 \mathrm{~b}$ & $96 \mathrm{a}$ & $11 \mathrm{a}$ & $12 \mathrm{c}$ \\
ÁGUAS & $80 \mathrm{~b}$ & $93 \mathrm{a}$ & $22 \mathrm{a}$ & $77 \mathrm{a}$ \\
\hline
\end{tabular}

Médias seguidas da mesma letra nas colunas não diferem entre si pelo teste de Tukey a $5 \%$ de probabilidade.

TABELA 3. Resumo das análises de variância referente ao efeito de cultivar, temperatura e local de coleta na germinação de sementes de Melinis minutiflora (capim-gordura). Distrito Federal, Brasil, 2004.

\begin{tabular}{crc}
\hline Causas de variação & \multicolumn{1}{c}{$\mathrm{F}$} & Pr $>\mathrm{F}$ \\
\hline Cultivar $(\mathrm{C})$ & 79,24 & $<0,0001$ \\
Temperatura $(\mathrm{T})$ & 1139,90 & $<0,0001$ \\
$\mathrm{C} * \mathrm{~T}$ & 9,57 & 0,0038 \\
Local $(\mathrm{L})$ & 22,96 & $<0,0001$ \\
$\mathrm{C} * \mathrm{~L}$ & 18,56 & $<0,0001$ \\
$\mathrm{~T} * \mathrm{~L}$ & 52,40 & $<0,0001$ \\
$\mathrm{C} * \mathrm{~T} * \mathrm{~L}$ & 14,60 & $<0,0001$
\end{tabular}

A diferença de germinação entre os testes em temperaturas alternadas, com nitrato e luz e em temperatura constante, em água e no escuro deve-se, provavelmente, à dormência das sementes. Aparentemente, sementes pouco dormentes germinaram em ambas as condições, ao passo que sementes com dormência mais acentuada somente germinaram nas condições mais promotoras (temperaturas alternadas). Dessa forma, consideraram-se dormentes as sementes que germinaram nas condições mais promotoras, porém 
deixaram de germinar nas condições menos promotoras (figura 1). Houve um efeito pronunciado do local de coleta na dormência das sementes, sendo as menos dormentes, nas duas cultivares, provenientes da Reserva Ecológica de Águas Emendadas.

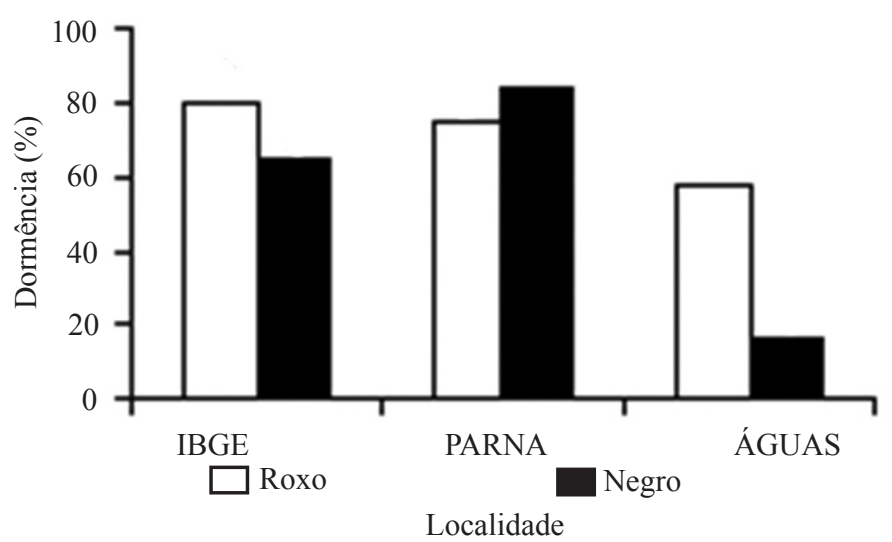

FIGURA 1. Dormência (\%) de sementes cheias de Melinis minutiflora (cultivares Roxo e Cabelo-deNegro), coletadas em diferentes localidades, avaliadas mediante a diferença de germinação entre os testes a $20-30{ }^{\circ} \mathrm{C}$, luz e nitrato de potássio e $25^{\circ} \mathrm{C}$, água e escuro, coletadas de diferentes áreas no Distrito Federal, Brasil, 2004. Médias seguidas da mesma letra em cada cultivar não diferem entre si pelo teste de Tukey a $5 \%$ de probabilidade.

Estudos conduzidos por Freitas e Pivello (2005) mostraram que as sementes de capim-gordura apresentavam ligeira dormência até um mês depois da colheita. Por sua vez, nas condições avaliadas, as sementes de capim-gordura estudadas ainda tinham elevada incidência de dormência primária (ou inata) mesmo após quatro meses da colheita, à exceção das sementes da cultivar Cabelo-de-Negro coletadas na Reserva Ecológica de Águas Emendadas (figura 1). Esses dados reforçam a hipótese de que há efeito das condições ambientais no desenvolvimento de dormência em sementes de capim gordura. A dormência é um dos fatores que podem explicar o sucesso do capim gordura em colonizar áreas de proteção ambiental na região central do Brasil. Aliado a isso, o capim-gordura se caracteriza por produzir grande quantidade de sementes com elevado poder germinativo e rápido crescimento vegetativo (Brasil, 1953).

Segundo Skerman e Rivers (1992), em condições de pastagens cultivadas, o capim-gordura pode alcançar uma produção de sementes de até $200 \mathrm{~kg} / \mathrm{ha}$. Por outro lado, Martins et al. (2004 b) relatam que em uma área de cerrado nativo colonizada espontaneamente em cerca de $50 \%$ por essa gramínea, a produção de sementes foi de 125 e $79 \mathrm{~kg} / \mathrm{ha}$ para as cultivares Roxo e Cabelo-de-Negro, respectivamente. Essas estratégias evolutivas possibilitam a essa espécie a formação de grandes bancos de sementes no solo (Freitas e Pivello, 2005; Martins, 2006). No Cerrado brasileiro, o capim gordura é considerado uma invasora bastante agressiva e que, uma vez estabelecido tanto em ambientes naturais quanto antropizados, tende a se consolidar e a se expandir nas áreas invadidas (Filgueiras, 1990; Martins et al., 2001; Martins et al., 2004 a).

Os resultados do presente trabalho ajudam a explicar a agressividade de colonização do capim gordura em áreas de proteção ambiental. A elevada viabilidade aliada à intensa dormência de sementes recém-colhidas dessa espécie constitui mecanismos importantes para o sucesso dessa espécie em colonizar novas áreas. Esses aspectos podem variar conforme o local em que as sementes são produzidas.

\section{CONCLUSÕES}

- Sementes recém colhidas de capim-gordura, das cultivares Roxo e Cabelo-de-Negro, têm elevados índices de viabilidade e de dormência.

- O local de coleta afeta o índice de esterilidade das espiguetas, a viabilidade e a dormência das sementes de capim gordura, cultivares Roxo e Cabelo-de-Negro.

- A viabilidade de sementes de capim-gordura pode ser avaliada por meio do teste de germinação com temperaturas alternadas de $20-30{ }^{\circ} \mathrm{C}$, em solução de nitrato de potássio a $0,5 \%$ na presença de luz e a dormência a $25^{\circ} \mathrm{C}$, em água e no escuro.

\section{AGRADECIMENTOS}

Ao IBAMA/Parque Nacional de Brasília, à Estação Biológica do IBGE (IBGE) e à Reserva Ecológica de Águas Emendadas pelas respectivas autorizações para as coletas das sementes do capim-gordura. À Professora Concepta Mcmanus Pimentel pelo auxílio nas análises estatísticas.

\section{REFERÊNCIAS}

ALLRED, K.W. Describing the grass inflorescence. Journal of Range Management, v.35, n.5, p.672-675, 1982. 
ARONOVICH, S.; ROCHA, G.L. Gramíneas e leguminosas forrageiras de importância no Brasil Central Pecuário. Informe Agropecuário, v.11, n.132, p.3-13, 1985.

BOGDAN, A.V. Tropical pasture and folder plants. New York: Longman, 1977. 475p.

BRASIL. Ministério da Agricultura. O capim-gordura. Rio de Janeiro, RJ: Seção de Agrostologia e Alimentação dos Animais, Publicação 6, 1953. 25 p.

BRASIL. Ministério da Agricultura e Reforma Agrária. Secretaria Nacional de Defesa Agropecuária. Departamento Nacional de Produção Vegetal. Coordenação de Laboratório Vegetal. Regras para Análise de Sementes. Brasília, DF, 1992. 365p.

BRASIL. Ministério da Agricultura. Normas, padrões e procedimentos para a produção de sementes no Distrito Federal. Brasília: Delegacia Federal de Agricultura no Distrito Federal. Seção de Fiscalização e Fomento da Produção Vegetal, 1998. 60p.

CARMONA, R.; MARTINS, C.R.; FÁVERO, A.P. Fatores que afetam a germinação de sementes de gramíneas nativas do cerrado. Revista Brasileira de Sementes, v.1, n.20, p.1622, 1998 .

CARMONA, R.; MARTINS, C.R.; FÁVERO, A.P. Características de sementes de gramíneas nativas do cerrado. Pesquisa Agropecuária, v.34, n. 6, p.1067-1074, 1999.

CURADO, T.F.C.; COSTA, N.M.S. Gramíneas para pastagens cultivadas em Minas Gerais. Informe Agropecuário, v.6, n.71, p.13-17, 1980.

FILGUEIRAS, T.S. Gramíneas africanas no Brasil introduzidas da África. Cadernos de Geociências, v.5, p.5763, 1990 .

FREITAS, G.K.; PIVELLO, V.R. A ameaça das gramíneas exóticas à biodiversidade. In: PIVELLO, V.R.; VARANDA, E.M. (Ed.). O cerrado Pé-de-Gigante: ecologia e conservação - Parque Estadual de Vassununga. São Paulo: Secretaria de Meio Ambiente, 2005. p. 240-270.

MARTINS, C.R.; LEITE, L.L.; HARIDASAN, M Recuperação de uma área degradada pela mineração de cascalho com uso de gramíneas nativas. Revista Árvore, v.2, n.25, p.157-166, 2001.

MARTINS, C.R.; LEITE, L.L.; HARIDASAN, M. Capimgordura (Melinis minutiflora P. Beauv.), uma gramínea exótica que compromete a recuperação de áreas degradadas em unidades de conservação. Revista Árvore, v.28, n.5, p.739-747, 2004a.
MARTINS, C.R.; HAY, J.D.V.; CARMONA, R.; LEITE, R.R.; SCALÉA, M.; VIVALDI, L.J.; PROENÇA, C.E.B. 2004 b. Monitoramento e controle da gramínea invasora Melinis minutiflora (capim-gordura) no Parque Nacional de Brasília, Distrito Federal. In: CONGRESSO BRASILEIRO DE UNIDADES DE CONSERVAÇÃO, 4, 2004, Curitiba. Anais... Curitiba: Fundação $\mathrm{O}$ Boticário de Proteção à Natureza: Rede Nacional Pró Unidade de Conservação, 2004 b, v.2, p.5-96.

MARTINS, C.R. Caracterização e manejo da gramínea Melinis minutiflora P. Beauv. (capim-gordura): uma espécie invasora do cerrado. 2006. 320f. Tese (Doutorado em Ecologia) - Instituto de Ciências Biológicas, Universidade de Brasília, Brasília, 2006.

MEAD, R.; CURNOW, R.N.; HASTED, A.M. Statistical methods in agriculture and experimental biology. Boca Raton, Florida: Chapman@ Hall/ CRC, 3 ${ }^{\text {rd }}$ ed. 2003,397p.

PARSONS, J.J. Spread of African pasture grasses to the America Tropics. Journal of Range. Management., v.25, p.12-17, 1972.

PIVELLO, V.R. An expert system for the use of prescribed fires in the management of Brazilian savannas. 1992. 238f. Thesis ( $\mathrm{PhD}$ in Ecology) - Imperial College of Science, Technology and Medicine, University of London, Ascot, 1992.

ROCHA, G.L.; CINTRA,B.; FREIRE, A; MONTANGUININI, M.F. Estudo da variação do teor germinativo de sementes de capim-gordura (Melinis minutiflora) armazenadas a baixas temperaturas e em ambiente normal. In: CONGRESSO INTERNACIONAL DE PASTAGENS, 9, 1966, São Paulo. Anais... São Paulo: Secretaria da Agricultura, 1966. v. 1, p.531-534.

SKERMAN, P.J.; RIVERS, F.R. Gramineas Tropicales. Roma: Coleción FAO - Producción y protección vegetal, 1992. $849 \mathrm{p}$.

VELlO, N. A. Comportamento e variabilidade em populações de capim-gordura (Melinis minutiflora Beauv.). 1975. 186f. Dissertação (Mestrado em Biologia) - Escola Superior de Agricultura "Luiz de Queiroz", Universidade de São Paulo, Piracicaba, 1975. 